\title{
Past Rates of Carbon Dioxide Changes and their Relevance for Future Climate
}

Thomas F. Stocker and ERIC Monnin

Climate and Environmental Physics, Physics Institute, University of Bern, 3012 Bern, Switzerland; stocker@climate.unibe.ch; monnin@climate.unibe.ch

Paleoclimatic data from the ice core from Vostok Station (Antarctica) provide the basis for one of the most fundamental statements of Global Change research: "The present $\mathrm{CO}_{2}$ concentration has not been exceeded during the past 420,000 years ... The current rate of increase is unprecedented during at least the past 20,000 years." (IPCC, 2001). These important findings are based on precise measurements of the $\mathrm{CO}_{2}$ concentration in air bubbles enclosed in Antarctic ice (Petit et al., 1999) and testifies to the fact that one of the primary forcing factors determining global climate has moved significantly above the bounds defined by natural climate change. How fast atmospheric concentrations of $\mathrm{CO}_{2}$ change, however, has attracted less attention essentially because only in the last few years, the resolution of the $\mathrm{CO}_{2}$ reconstruction has increased sufficiently to permit calculations of rates of change.

Since 1999 we have worked on high-resolution records of $\mathrm{CO}_{2}$ within two major projects. The first was a collaboration with Martin Wahlen from the Scripps Institute of Oceanography, in which highresolution records of the Holocene and the Last Glacial (60-20 kyr BP) were measured. The samples were obtained from the ice core from Taylor Dome (Antarctica) drilled by a US team. The second ice core comes from Dome Concordia (Antarctica) which was drilled as part of EPICA (European Project of Ice Coring in Antarctica), funded by the European Commission and the participating ten European nations. Thanks to the excellent core quality of these polar ice cores, $\mathrm{CO}_{2}$ measurements on samples of less than 10 grammes of ice reach an average reproducibility of $1.5 \mathrm{ppmv}$ using Laser Absorption Spectroscopy.

In determining rates of change based on gas records from ice

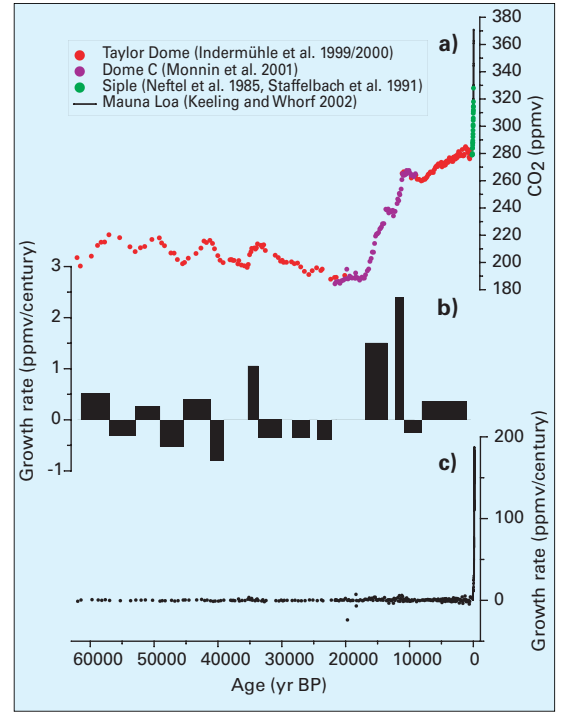

Fig. 1: Composite high-resolution $\mathrm{CO}_{2}$ records based on measurements of air enclosed in bubbles in two Antarctic ice cores from Taylor Dome and Dome Concordia. (a) $\mathrm{CO}_{2}$ concentrations (red: Taylor Dome (Indermühle et al., 1999; Indermühle et al., 2000); purple: Dome Concordia (Monnin et al., 2001); green: Siple Station (Neftel et al., 1985; Staffelbach et al., 1991)l, including the direct measurements from Mauna Loa (black line, (Keeling and Whorf, 2002)). (b) Estimated mean rates of $\mathrm{CO}_{2}$ changes evolving over several millennia, calculated as the ratio between neighbour ing relative maxima and minima divided by the time difference. Positive and negative rates are distinguished; the former fall into two classes. (c) rates between neighbouring measurements including the last 250 years during which the rates are about 100 times larger than anytime during the last 60,000 years. Through the values from Siple Station and Mauna Loa a spline function with a cutoff period of 10 years was fitted in order to remove the annual variability.

cores, one must address the problem of the enclosure process of gases in the ice. Before air bubbles are enclosed, gases are residing in the porous firn column with a depth of 80-120 meters, which overlies the ice. This leads to two important effects: (i) the gas-age/ice-age difference, and (ii), the age distribution of gas between different air bubbles within one sample. The first effect is relevant in the construction of the age scale and hence influences the calculation of rates of concentration changes. This effect is taken into account. The second is important only if abrupt and large changes of concentrations of trace gases occur in the atmosphere. Such rapid changes would be damped due to the primarily diffusive exchange of gases within the firn column and the somewhat erratic character of the close-off process. If one is to determine rates over very short time scales (centuries or less), this damping effect must be taken into account. Here, however, we first focus on mean rates over time intervals of several centuries to millennia, in which case the latter effect is not relevant.

Figure 1a shows a composite record of high-resolution $\mathrm{CO}_{2}$ reconstructions for the last 60,000 years and the average rates of change for millennial intervals. In the Glacial and the Holocene, the data are from Taylor Dome (Indermühle et al., 1999; Indermühle et al., 2000), and the deglaciation is measured on ice from Dome Concordia (Monnin et al., 2001). As observed by Indermühle et al. (2000), the relative $\mathrm{CO}_{2}$ maxima between 60 and 20 kyr BP are strongly correlated with the four Antarctic warming events during this interval (Blunier et al., 1998). The $\mathrm{CO}_{2}$ changes therefore occur on a millennial time scale rather than the faster time scale characteristic of the sequence of abrupt warmings in the northern hemisphere known as Dansgaard/ Oeschger events. This is an important biogeochemical constraint for models simulating abrupt climate change during the glacial and one of the strong indicators that the Southern Ocean must have played a key role in the $\mathrm{CO}_{2}$ changes. Rates of change were calculated by identifying neighbouring relative maxima and minima, whose difference exceeds $6 \mathrm{ppmv}$, and then interpolating linearly the values between neighbouring minima and maxima. Before the anthropogenic increase of $\mathrm{CO}_{2}$ starting in the $18^{\text {th }}$ century, the positive rates $\left(\mathrm{CO}_{2}\right.$ increase $)$ fall 


\section{Science Highlights}

into two distinct classes (Fig. 1b). Changes during the glacial and the Holocene exhibit mainly rates of about $0.5 \mathrm{ppmv} / \mathrm{century}$, whereas the rate of increase is $3-5$ times higher during deglaciation, reaching about 1.5 to $2.5 \mathrm{ppmv} / \mathrm{century}$. In constrast, negative rates appear rather uniform with about 0.3 to $0.8 \mathrm{ppmv} / \mathrm{century}$. There are also extended intervals during which the $\mathrm{CO}_{2}$ concentrations change by less than 6 ppm for several 1000 years. In terms of natural $\mathrm{CO}_{2}$ changes, deglaciation appears as the time interval during which the fastest changes occurred. One should note that our determination of rates explicitly excludes step-like features such as those found by Monnin et al. (2001); the associated $\mathrm{CO}_{2}$ increase is typically 10 ppmv or less. Larger decadal deviations in $\mathrm{CO}_{2}$ (e.g., " $\mathrm{CO}_{2}$ pulses») are very unlikely because large concentration changes would be detected at the current sample resolution. The $\mathrm{CH}_{4}$ increase of $140 \%$ in two centuries at the Younger Dryas termination provides a good argument that large increases of atmospheric greenhouse gas concentrations can be recorded in the Dome Concordia ice core.

The positive $\mathrm{CO}_{2}$ growth rates during the series of Antarctic warmings were smaller than those during deglaciation. As shown in model simulations, this variability can, at least in part, be explained by complete shutdowns of the Atlantic thermohaline circulation (Marchal et al., 1998). The model, however, severely underestimated the $\mathrm{CO}_{2}$ amplitude by about a factor of 2 , indicating that other effects, such as changes in the ocean chemistry of the Southern Ocean, or changes in sea ice cover might have contributed to the $\mathrm{CO}_{2}$ amplitude (Keeling and Visbeck, 2001). $\mathrm{CO}_{2}$-increases are significantly faster during deglaciation. This might indicate that the pace of forcing dictated the $\mathrm{CO}_{2}$ rate during that period. Based on the available coarse record of isotopic data, we favoured a mechanism which postulated a strong release of terrestrial biomass during the Holocene (Indermühle et al., 1999).
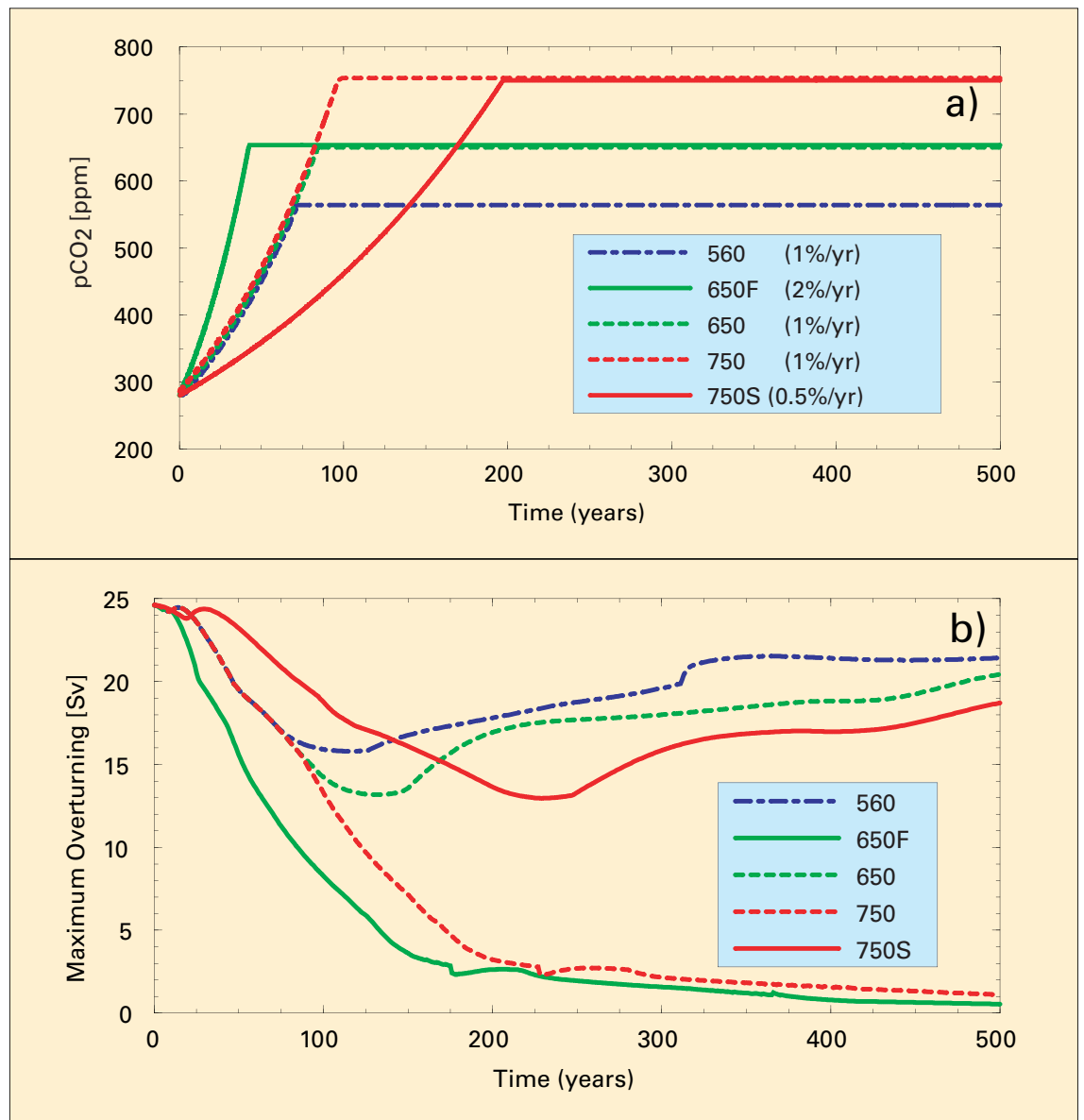

Fig. 2: (a) Simulations using a reduced complexity climate model exhibit a bifurcation of the Atlantic meridional overturning circulation in global warming experiments. $\mathrm{CO}_{2}$ is increased at a constant rate (compounded) up to a fixed level. (b) Maximum Atlantic meridional overturning circulation. Warming generally leads to a reduction of the circulation. If the warming or the rate stay below certain thresholds, the response of the circulation is linear. Otherwise, an irreversible transition to a second equilibrium solution results. Crossing of the threshold depends on the rate of $\mathrm{CO}_{2}$ increase. (Figure from Stocker and Schmittner, 1997)

However, shell weight changes and foraminiferal size indices suggest that the Holocene $\mathrm{CO}_{2}$ increase might have been due to a combination of a net growth of the terrestrial biosphere at the end of the Last Glacial and the subsequent calcium carbonate compensation of the ocean (Broecker and Clark, 2003). Until we produce a reliable ${ }^{13} \mathrm{C}$ record with a resolution comparable to that of the $\mathrm{CO}_{2}$ record, this important problem cannot be resolved.

The increase of the concentration of $\mathrm{CO}_{2}$ and other greenhouse gases in the atmosphere is responsible for a large part of the observed warming since the beginning of the $20^{\text {th }}$ century (IPCC, 2001). Apart from the continued global warming and sea level rise that is predicted by all climate models under all emissions scenarios, the majority of coupled models also simulates a decrease of the meridional overturning circulation in the Atlantic Ocean during the next 100 years. Due to nonlinearities associated with this circulation, thresholds are believed to exist beyond which this circulation may completely cease (Stocker and Wright, 1991). Such a transition might well be irreversible, i.e. even if $\mathrm{CO}_{2}$ concentrations in the atmosphere returned back to preindustrial levels many centuries hence, the overturning circulation would not reestablish itself. This reorganisation in the ocean circulation would have wide ranging consequences for the climate in regions influenced by the Atlantic Ocean.

In a series of simulations it was demonstrated that the proximity of the threshold, beyond which the circulation collapses, depends on the rate of warming, and therefore on the rate of $\mathrm{CO}_{2}$ increase (Stocker and Schmittner, 1997). This is illus- 
trated in Figure 2. A transition to a state with no overturning circulation in the Atlantic Ocean occurs if the maximum warming exceeds a certain threshold. In addition to the level of achieved warming, also the rate of the warming is crucial. Faster warmings lead to lower thresholds, while slower warming makes the system more permissible and a larger warming can be achieved without a cessation of the overturning circulation. This was the first indication of a physical process which caused fundamentally different climate responses might result from slightly different emissions scenarios. These findings make a strong case for "early action" on $\mathrm{CO}_{2}$ emissions reductions in order to keep away from potentially dangerous thresholds.

The increasing quality of paleoclimatic records, and the establish- ment of reliable time scales now allow the investigation of the rate of change of certain quantities. Such information provides important constraints for models simulating past climate changes. The quantification of $\mathrm{CO}_{2}$ rates is potentially important in helping to disentangle the different mechanisms that are responsible for the observed changes. $\mathrm{CO}_{2}$ rate will also play a crucial role in future climate change since they influence the proximity of certain thresholds in the climate system. Such thresholds could hold unwanted surprises of change. By paying special attention to $\mathrm{CO}_{2}$ growth rates, and their possible limitation by carefully selecting emission paths in the future, such surprises may be successfully avoided (Alley et al., 2003).

\section{REFerences}

Alley, R.B., Marotzke, J., Nordhaus, W.D., Overpeck, J.T., Peteet, D.M., Pielke Jr., R.M., Pierrehumbert, R.T., Rhines, P.B., Stocker, T.F., Talley L.D. and Wallace, J.M., 2003: Abrupt climate change. Science, in press.

Blunier, T., Chappellaz, J., Schwander, J., Dällenbach, A., Stauffer, B., Stocker, T.F., Raynaud, D., Jouzel, J., Clausen, H.B., Hammer, C.U. and Johnsen, S.J., 1998: Asynchrony of Antarctic and Greenland climate change during the last glacial period. Nature, 394, 739-743.

Indermühle, A., Stocker, T.F., Joos, F., Fischer, H., Smith, H.J., Wahlen, M., Deck, B., Mastroianni, D. Tschumi, J., Blunier, T., Meyer, R. and Stauffer, B., 1999: Holocene carbon-cycle dynamics based on $\mathrm{CO}_{2}$ trapped in ice at Taylor Dome, Antarctica. Nature, 398, 121-126.

IPCC, 2001: Climate Change 2001: The Scientific Basis. Contribution of Working Group I to the Third Assessment Report of the Intergovernmental Panel on Climate Change. [Houghton, J.T., et al. (eds.)]. Cambridge University Press, Cambridge, $881 \mathrm{pp}$.

Stocker, T.F. and Wright, D.G., 1991: Rapid transitions of the oceans deep circulation induced by changes in surface water fluxes. Nature, 351, 729-732.

For full references please consult:

www.pages-igbp.org/products/newsletters/ref2003_1.html

\title{
Rates of Change in the Upper Treeline Ecotone in the Polar Ural Mountains
}

\author{
Stepan G. Shiyatov
}

Institute of Plant and Animal Ecology (Ural Branch of the Russian Academy of Sciences), 620144 Ekaterinburg, Russia, stepan@ipae.uran.ru

Significant spatio-temporal changes took place in the upper treeline ecotone in the Polar Ural Mountains $\left(66-67^{\circ} \mathrm{N}, 65-66^{\circ} \mathrm{E}\right)$ during the last millennium (Shiyatov, 1993, 1995). Within the treeline ecotone, which is located from 100 to $350 \mathrm{~m}$ a.s.l., Siberian larch (Larix sibirica) open forests dominate. Patches of larchspruce (Picea obovata) closed forests grow at lower altitudinal levels in the ecotone. Up to this day, these forests have been mainly developing under the influence of natural factors. There are a great number of wood remnants on the ground up to $60-80 \mathrm{~m}$ above the present treeline and within the ecotone that have been preserved for a long time (up to 1300 years) because of the low rate of wood decomposition in severe climatic conditions. These provide us with the possibility of extending ring-width chronology back to $645 \mathrm{AD}$ and of dating the lifetime of a large quantity of dead trees. In order to estimate displacement of the upper treeline (the highest

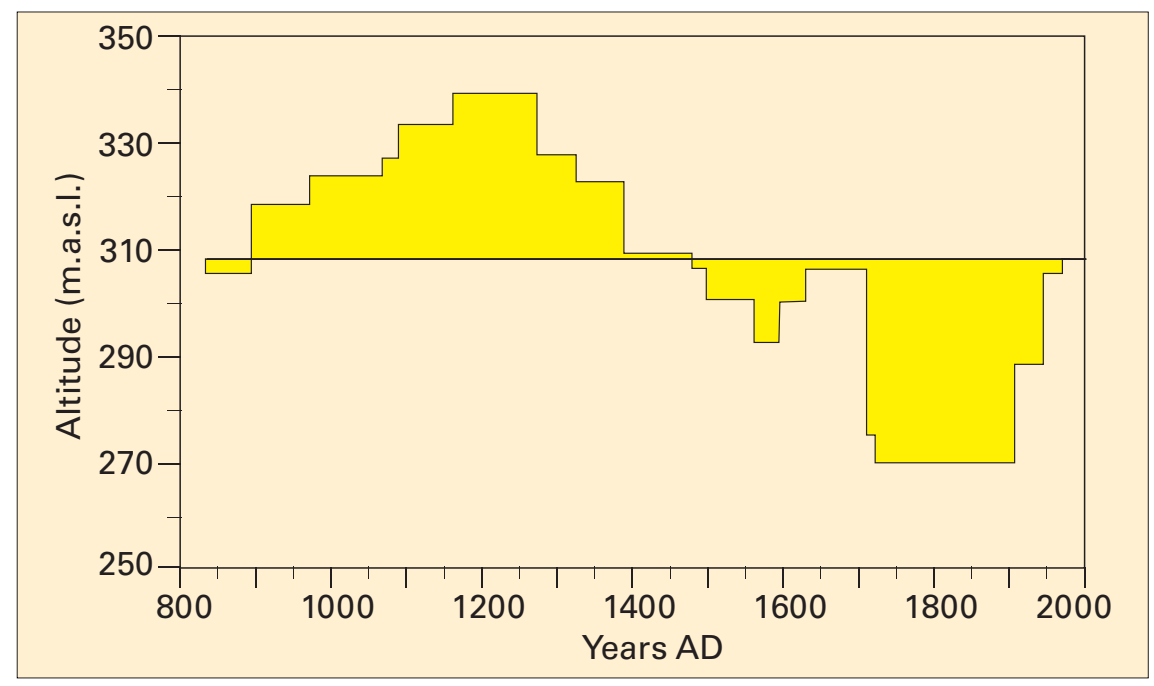

Fig. 1. Altitudinal displacement of the upper treeline in the Polar Ural Mountains during the last 1150 years.

altitudinal position of open forests) over the last millennium, a transect $430 \mathrm{~m}$ long and $20 \mathrm{~m}$ wide was set up on the south-eastern slope of Rai-Iz Massif, from the highest location of larch wood remnants (340 $\mathrm{m}$ a.s.l.) to the present upper treeline $(280 \mathrm{~m})$. The transect was divided into $10 \times 10 \mathrm{~m}$ quadrates. All of the wood remnants were mapped and cuts from the base of trunk and roots were collected from each individual tree. Calendar years of establishment and dying off were determined by dendrochronological techniques. Altogether, a time span of 270 dead trees was defined. In addition, 16 young living trees and seedlings were also mapped and their age determined. 